\title{
AC 2010-1668: EVALUATING THE EFFECTIVENESS OF MENTORING DOCTORAL STUDENTS FOR ACADEMIC CAREERS
}

\section{Carla Purdy, University of Cincinnati}

Carla C. Purdy is an Associate Professor in the Department of Electrical and Computer Engineering at the University of Cincinnati, where she also directs the College of Engineering's Preparing Future Faculty program. Her research interests include intelligent embedded systems, bioinformatics, and computer simulations of biomolecular systems. 


\title{
Evaluating the Effectiveness of Mentoring Doctoral Students for Academic Careers
}

\begin{abstract}
For students graduating with a Ph.D. in engineering today and opting for an academic career, the path to eventual promotion and tenure is likely to be long and difficult. While new Ph.D.s may understand the importance of continuing to do cutting-edge research, establishing a solid funding record, and obtaining strong teaching recommendations, there are many other factors important to career success of which they may be unaware. For example, they may have little knowledge of how formal promotion and tenure rules may be interpreted by their colleagues, what an annual performance evaluation really means, how to establish a good network of mentors with whom to discuss important career decisions, or how to realistically gauge their own progress or lack thereof and take any corrective action needed at the particular institution where they are employed. The question of how to ensure that our graduates have a sufficient understanding of both the formal rules and the common assumptions of academic culture, while they are focusing most of their energies on solving challenging research questions, is a difficult one. However, many institutions today are providing enrichment programs for their Ph.D. students that encourage them to acquire teaching skills, along with their research skills. Such programs may also provide some coaching for academic job searches. For the past ten years, the University of Cincinnati's Department of Electrical \& Computer Engineering has conducted a Preparing Future Faculty in Engineering program, a series of seminars for advanced Ph.D. students. This program originally focused on improving teaching skills but has increasingly incorporated career advice, not only for obtaining an initial position but also for establishing a successful academic career. In this paper, we survey participants from this program to determine their perceptions of the effectiveness of these career-building components. Our overall goal is to strengthen this aspect of our program, without detracting from its original purpose of developing teaching skills. As our program is designed to be flexible and resource-moderate, any effective strategies which we develop can be replicated to provide better overall career training for Ph.D. students at many other institutions.
\end{abstract}

\section{Introduction}

The Preparing Future Faculty (PFF) in Engineering program at the University of Cincinnati (UC) was originally established in 1999 to carry out the goals defined by the national PFF program ${ }^{1}$, i.e., to prepare Ph.D. students to teach and to provide them with multiple mentors. At the time, there were many job opportunities for engineering faculty in general and for computer science faculty in particular. Thus the UC PFF program ${ }^{2,3}$ focused on providing information on modern teaching techniques, some practical teaching experience, and basic information on how to be successful in an academic job search. An integral part of the UC program, as with all PFF programs, has been introducing the student participants, who are earning Ph.D. degrees in research universities, to the possibility of more teaching-focused careers in institutions serving undergraduates. At UC, practical experience and mentoring in a teaching-focused 
program could be obtained by PFF participants in the University's College of Applied Science, which offers two-year and four-year technology degrees in many fields. But changes in career prospects for new engineering Ph.D.'s, along with major changes in academic programs at UC, are providing the impetus for changes in the PFF program. We describe some motivating factors in the changes we have made and are making and we describe an ongoing survey to obtain input from past participants and to measure the effectiveness of those changes.

\section{Academic Jobs in Engineering}

In the years since the UC program was established, the academic job situation in most engineering fields has changed considerably. Academic positions, especially tenure-track positions, are few and far between. Currently, as universities struggle with budget issues during the economic downturn, there are very few tenure-track positions available. In addition, many universities are increasing standards for hiring and promotion, especially in research, as they strive to increase national rankings in polls run by organizations such as U.S. News and World Reports ${ }^{4,5}$ and by organizations more focused on ranking research programs. This means that expectations for a faculty member's performance may shift in the five or six years between hiring and a tenure decision. Many more Ph.D. students in engineering are finding that one or two or even three postdoctoral positions are desirable or necessary before they take a regular faculty position ${ }^{6}$, and thus information on how to have a successful post-doc experience is also important.

\section{Changes in UC's Academic Programs}

Two major changes in UC's academic structure are currently driving the need to reevaluate courses and programs. These are a move from the quarter system to the semester system and a merger of the College of Engineering with the College of Applied Science.

The change from quarters to semesters, which is being undertaken at many of the state educational institutions in Ohio, is scheduled to be completed by Fall 2012. This change is significant for the UC College of Engineering, which has a mandatory co-op program for its undergraduates. Currently an undergraduate engineering major at UC spends five years earning the B.S. degree, with six months of co-op employment in each of the middle three years. Modifying the curriculum to fit into a semester system is a major undertaking which also is affecting graduate programming, including the PFF program, especially since the change is being seen as a way to streamline programs in general. Thus, for example, in some graduate engineering programs, Ph.D. and even M.S. candidates will be required to take some seminars to develop professional skills. And it is possible that some of the topics currently covered in the PFF program will now be covered in departmental seminars. This will free up time in the PFF program for additional topics, and it is important to identify what topics will be most valuable for participants. 
The merging of the College of Engineering with the College of Applied Science, which will be official in July 2010, will also have a major effect on many aspects of the PFF program. All current departments are being restructured into schools, with most schools scheduled to offer graduate degrees, undergraduate engineering degrees, and undergraduate four-year technology degrees. Most if not all two-year degree programs will be phased out. Faculty in each school will thus be a mix of faculty who up to now were more focused on research and faculty who up to now were more focused on teaching. This new structure can offer many advantages for both faculty and students, but there are many issues still to be resolved to achieve benefits for all concerned. For the PFF program, there will be the opportunity for participants to interact more directly with faculty who are focused on research and with faculty who are more focused on teaching. In addition, a new department, the Department of Engineering Education, is being created in the Engineering College, and this department's programs and research can be a good source of information for PFF participants. Currently this fledgling department is already working on improving freshman retention through tutoring programs and a restructuring of the freshman Introduction to Engineering course, which will become mandatory for all freshmen when the move to semesters is completed. Thus there are good potential opportunities for PFF participants to be involved with these courses and to be exposed to engineering education research projects.

\section{Information on Academic Careers and on Engineering Education}

As mentioned, UC already has a nascent Engineering Education Department, whose programs can serve as an additional resource for PFF in Engineering students. Much useful information is also being generated by the two already well established Engineering Education programs, at Purdue and at Virginia Tech ${ }^{7,8}$. In addition, information on academic careers in engineering and science is available from a number of sources, for example, in the book by Davidson and Ambrose ${ }^{9}$ and in the book by Reis $^{10}$, along with its associated website ${ }^{11}$. But in keeping with the original PFF goals ${ }^{1}$, participants still need an assigned mentor (or mentors) for the program to function as it is supposed to.

\section{Evolution of the UC PFF in Engineering Program}

The UC PFF in Engineering program has been evolving gradually to better serve the needs of today's Ph.D. students. Initially it consisted on a one-quarter seminar on teaching, a one-quarter seminar on the job search, and a 10-hour mentoring experience. Modifications since its inception include an additional one-quarter seminar on advanced teaching techniques which includes information on subjects such as Bloom's taxonomy, ABET, adding practical ethics instruction to engineering courses, and proposal-writing focused on an REU application, as well as more information in the job search seminar on how to establish and maintain a successful career and how to continue to identify mentors. Lee, Papautsky, and Purdy have provided a description of the current PFF in Engineering program $^{12}$. 
In addition, better synchronization with UC's university-wide PFF program has been achieved. Two significant differences between the PFF in Engineering program and the university-wide program are the requirements for joining the program and the requirements for the mentoring component. The Engineering program only accepts participants after they have passed their doctoral qualifying examination, while the University program accepts even first-year students who may not be classified as Ph.D. students yet. And the Engineering program, which was designed to be light-weight and flexible so as to mesh well with participants' research commitments, requires only ten hours of work with the mentor, while the university-level program requires 30 hours. There is also an added benefit to completing the university program, aside from the valuable extra mentoring experience, since the university program is a certificate program, which the engineering program provides only course credit on the participant's transcript. But there is now a well-defined path for students who complete the engineering program to fulfill additional requirements and to receive the PFF certificate. One student has completed both programs this way and several others are in the process of doing so.

\section{Assessing and Improving the PFF in Engineering Program}

Although the PFF in Engineering program, like other graduate programs, is not vetted periodically by ABET, an informal process of assessment and improvement has been ongoing since its inception. But in light of the many new challenges for program graduates and the many changes in the UC academic structure, a more formal assessment is in order. Thus we have embarked on a project to survey past participants (there are well over 100 "graduates" since the program began in 1999) to see what changes will be most beneficial for future participants. We are also setting up a website for current and past participants to encourage mentoring of newer participants by PFF in Engineering graduates. The survey of past participants is still ongoing, since contact information for some past participants has been difficult to obtain. But we do have data for recent participants and some anecdotal evidence to present at this time.

\section{Survey Results-Recent Participants}

Survey questions are shown in Figure 1 below. Complete survey results from the past year are available. Ten students, from seven different departments, were enrolled in the course sequence that started in Winter 2009 (Teaching Techniques, Advanced Teaching Techniques, Mentoring Experience, The Academic Profession), and all of these students completed the survey.

For question two, all students indicated that the all the goals except for mentoring undergraduate students and making career decisions were important or very important. Two students indicated that mentoring undergraduate students was not important and one indicated that it was not applicable. Two students indicated that help in making career decisions was not important (presumably because they believe they have already made their main career decision). Answers to how valuable the activities were (question 3)

mirrored answers to question 2. All students said they would recommend the program to 
other graduate students. For seven of the ten students, the faculty panels on the job search were the most valuable part of the program. Other choices for "most valuable" included proposal-writing (3), and how to give a presentation, writing a vita, and teaching techniques ( 2 each); (some students listed more than one "most valuable" component). Choices for "most important" aligned almost perfectly with the "most valuable" choices.

Seven students said that "none" of the activities were "least valuable", while two said the activities related to grant-proposal writing were least valuable and one mentioned the panel on what is important for a positive tenure decision (although this student pointed out that this was a useful topic, just perhaps too early to think about).

Suggestions for improvements included "none" (3), more practice in teaching or giving presentations (3), more faculty discussion panels (2), and more on grant proposal writing and challenges for international students (1 each). One respondent wanted the opportunity to earn a certificate (which is now possible through the better synchronization between Engineering PFF and university-level PFF). .

\section{Input from Past Participants}

Although the survey of participants in previous years is not yet complete, many of the improvements suggested by the recent participants are in line with anecdotal evidence from participants who completed the program earlier. The biggest mismatch seems to be in understanding the importance of learning good proposal-writing skills and also in understanding the importance of managing one's career and learning the unwritten rules of the institution where one is employed.

Thus, although the survey is not yet complete, we already have some good pointers for how to improve our program as we adjust to the changes in the UC Engineering academic structure. We will need to add more panels to program, where faculty and students can interact and where the importance of having five- or ten-year career plans is stressed. And we will probably start requiring attendance at UC's day-long grant-writing workshop for all participants. More practice in teaching should also be easier to arrange as the College of Engineering and College of Technology programs and faculty become better integrated.

\section{Conclusions}

With major changes in UC's academic structure in progress or planned for the near future, now is an optimal time to assess and plan for improvements to the UC PFF in Engineering program. Partial results from a survey of PFF in Engineering participants and anecdotal evidence from previous participants has suggested several improvements that can be made. Results so far also indicate that the program as currently structured is considered valuable and important by the great majority of students who have taken part in it. 


\section{UC PFF in Engineering Survey}

Directions: Please respond to the following 9 questions as fully as possible. Thank you for agreeing to participate in our survey

1. Please provide the following background information:

- Sex Male Female

- Race/Ethnicity: Asian, Black, Latino/Latina, Native American/Alaskan Native, Native Hawaiian/Pacific Islander, White

- Citizenship: U.S. citizen U.S. Permanent Resident Other

- Country in which you did your undergraduate training

- Date doctoral degree expected / awarded:

- Discipline of doctoral degree

- Present position and title:

- Academic year and quarter you began PFF participation

- Did you participate in any University-level PFF program seminars or reading groups?

- Did you participate in the University-level PFF mentoring program?

2. How important were the following goals in your decision to participate in PFF (rank 1-4, with 1 not important and 4 very important, or N/A):

- To learn about faculty roles

- To learn about the expectations that different institutions have of faculty

- To gain teaching experience and guidance

- To mentor undergraduate students

- To help you make career decisions

- To help you in your job search process

- To broaden/strengthen your credentials

- Other (Please specify)

3. Please check all the PFF activities in which you have participated and assess the value of each:

- Teaching seminar(s)

- Seminar on academic life and the job search

- Faculty panels on the job search

- Faculty-led discussion on important issues related to promotion and tenure

- Faculty mentoring experience

- Mentoring an undergraduate student

- Writing effective proposals workshop

- Attending a national conference

- $\quad$ Project(s) at partner institution(s)

4. Please describe the MOST valuable part of your PFF experience; why was it valuable to you?

5. Please describe the LEAST valuable part of your PFF experience; why was it not valuable?

6. Please describe the impact PFF participation had on your graduate school experience.

7. Would you recommend PFF participation to other graduate students? Why or why not?

8. If you are currently employed, do you believe that PFF was a factor in getting this position? Please explain WHY or WHY NOT below.

9. What recommendations do you have for improving UC's PFF program in Engineering?

Figure 1. UC PFF in Engineering Survey--Questions 


\section{Bibliography}

1. http://www/preparing-faculty.org, accessed April 2, 2010.

2. G. Lewandowski and C. Purdy, Training Future Professors: The preparing future faculty (PFF) program in electrical and computer engineering and computer science at the University of Cincinnati, Proceedings 2001 ASEE Conference, Albuquerque, NM, June 2001.

3. C. Purdy, G. Lewandowski, J. Hauser, and S. Coppock, Establishing and sustaining a preparing future faculty program in electrical and computer engineering and computer science, Journal on Excellence in College Teaching 17 (1\&2), 2006, 37-59.

4. http://colleges.usnews.rankingsandreviews.com/best-colleges/engineering, accessed April 2, 2010.

5. http://grad-schools.usnews.rankingsandreviews.com/best-graduate-schools/top-engineering-schools, accessed April 2, 2010.

6. Committee on Science, Engineering, and Public Policy (COSEPUP), Enhancing the Postdoctoral Experience for Scientists and Engineers: A Guide for Postdoctoral Scholars, Advisers, Institutions, Funding Organizations, and Disciplinary Societies, National Academies Press, 2000.

7. Purdue University School of Engineering Education, https://engineering.purdue.edu/ENE/, accessed April 2, 2010.

8. Virginia Tech Department of Engineering Education, http://www.enge.vt.edu/, accessed April 2, 2010.

9. The New Professor's Handbook: A Guide to Teaching and Research in Engineering and Science, Cliff I. Davidson and Susan A. Ambrose, Jossey-Bass (Wiley), 1994.

10. Tomorrow's Professor, Preparing for Academic Careers in Science and Engineering, Richard M. Reis, IEEE Press, 1997.

11. Tomorrow's Professor blog, http://tomprofblog.mit.edu/. Accessed April 2, 2010.

12. J.-H. Lee, I. Papautsky, and C. Purdy, Experiences and benefits for a graduate student in a preparing future faculty program in engineering, Proc. 2009 ASEE Annual Conference. 